WellBeing International

WBI Studies Repository

$9-1990$

\title{
Inferences About Guessing and Knowing by Chimpanzees (Pan troglodytes)
}

\author{
Daniel J. Povinelli \\ Yale University \\ Kurt E. Nelson \\ The Ohio State University \\ Sarah T. Boysen \\ The Ohio State University
}

Follow this and additional works at: https://www.wellbeingintlstudiesrepository.org/acwp_asie

Part of the Animal Studies Commons, Comparative Psychology Commons, and the Other Animal Sciences Commons

\section{Recommended Citation}

Povinelli, D. J., Nelson, K. E., \& Boysen, S. T. (1990). Inferences about guessing and knowing by chimpanzees (Pan troglodytes). Journal of Comparative Psychology, 104(3), 203.

This material is brought to you for free and open access by WellBeing International. It has been accepted for inclusion by an authorized administrator of the WBI Studies Repository. For more information, please contact wbisr-info@wellbeingintl.org.

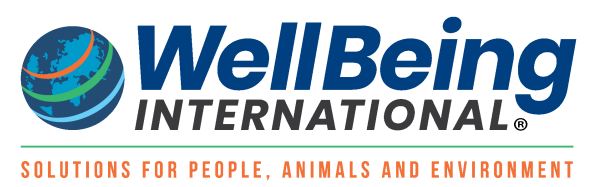




\title{
Inferences About Guessing and Knowing by Chimpanzees (Pan troglodytes)
}

\author{
Daniel J. Povinelli ${ }^{1}$, Kurt E. Nelson ${ }^{2}$, and Sarah T. Boysen ${ }^{2,3}$ \\ ${ }^{1}$ Yale University \\ ${ }^{2}$ Ohio State University \\ ${ }^{3}$ Emory University
}

\section{ABSTRACT}

The visual perspective-taking ability of 4 chimpanzees (Pan troglodytes) was investigated. The subjects chose between information about the location of hidden food provided by 2 experimenters who randomly alternated between two roles (the guesser and the knower). The knower baited 1 of 4 obscured cups so that the subjects could watch the process but could not see which of the cups contained the reward. The guesser waited outside the room until the food was hidden. Finally, the knower pointed to the correct cup while the guesser pointed to an incorrect one. The chimpanzees quickly learned to respond to the knower. They also showed transfer to a novel variation of the task, in which the guesser remained inside the room and covered his head while the knower stood next to him and watched a third experimenter bait the cups. The results are consistent with the hypothesis that chimpanzees are capable of modeling the visual perspectives of others.

Despite the recent resurgence of interest in primate social intelligence, there is still little empirical evidence that nonhuman primates possess the attributional capacities that some investigators suggest may motivate much of their behavior (e.g., Humphrey, 1980; Whiten \& Byrne, 1988). Primates do appear to know much more about their own social systems than we had previously suspected (Cheney, Seyfarth, \& Smuts, 1986). They also appear to be capable of sophisticated forms of behavior that lead to manipulation and deception of others (Whiten \& Byrne, 1988). For example, during Rummer's (1967) early work with hamadryas baboons, he witnessed females presenting and glancing at males while threatening rival females. He speculated that one possible function of this behavior was to manipulate the males into attacking the challenging females. Bachmann and Rummer (1980) later reported experimental evidence that males of the same species were able to judge the quality of newly established male-female pairs and then use that assessment to decide whether to intervene and attempt to lead the females away. Smuts (1986) recently provided intriguing preliminary evidence that after aggressive encounters with more dominant animals, savanna baboons may wait to retaliate surreptitiously and selectively against the relatively subordinate companions of that animal. Despite such sophisticated social maneuvering, do most primates possess a capacity to represent the mental states of others? As Premack and Woodruff (1978) put it, do they have an ability that allows them to make inferences about the intentions, desires, and states of mind of others? 
Given the difficulties of devising experimental methods applicable to addressing these questions in the field, Whiten and Byrne (1988) set about the task of trying to develop a taxonomy of mind by collating a vast array of anecdotal descriptions of primate deception (e.g., deWaal, 1986). As did Humphrey (1980), they described primates as natural psychologists, capable of representing the mental states of each other and using these representations to deceive others. One example cited by Whiten and Byrne is the observation by field-workers of subordinate males of a variety of species that carefully adjusted their behavior to allow them to copulate with females while out of sight of dominant males. The interpretation they favor is not simply that the subordinates have learned through aversive trial-and-error learning to avoid mating with females when dominant males are visible but rather that the subordinate males have a representation of the knowledge possessed by the dominant ones. If true, this implies that the subordinate males have a causal theory of knowledge of the type that allows them to make the following inference: If I am able to get out of sight of the dominant animal, then it will not be able to see me, therefore that male will not know that I am mating with this female.

Such an understanding requires a capacity for visual perspective taking, the ability to understand how objects and events may appear from another's perspective. It also requires the ability to understand that a different visual perspective may lead another animal to possess a different state of knowledge than oneself (Premack, 1988). The development of these abilities in human infants has been well documented (Borke, 1971; Lempers, Ravell, \& Flavell, 1977; Masangkay et al., 1974; Mossier, Marvin, \& Greenberg, 1976; Wimmer, Hogrefe, \& Perner, 1988; Zahn-Waxier, Radke-Yarrow, \& Brady-Smith, 1977). In contrast, comparable experiments with nonhuman primates have not yet been conducted. Thus, it remains very possible that simpler mechanisms may account for the behaviors isolated by Whiten and Byrne (1988) as evidence of what they refer to as mind-reading (Cheney et al., 1986; Mitchell, 1986). However, despite the absence of comparative, empirical investigations directly focused on the issue of perspective taking, there have been a number of previous efforts to investigate directly related aspects of these issues in nonhuman primates.

In a series of experiments with a group of young chimpanzees in a large outdoor enclosure, Menzel (1974) explored aspects of leadership and communication. He was able to demonstrate that chimpanzees who were shown the location of hidden food by human experimenters were successful in attracting naive chimpanzees to follow them to the location of the reward. These leaders used a variety of methods to entice the other chimpanzees into following them, including tapping them on the shoulder, repeatedly glancing at them while heading in the direction of the food, and "in the extreme case, screaming, grabbing a preferred companion, and dragging him in the direction of the food" (Menzel, 1974, p. 115). Later, the followers seemed to know which animal best knew the location of the food and readily followed that animal to the correct spot. Although it seems clear that the followers were responding to direct cues from the leader's behavior (Menzel, 1974), it is also possible that the followers were able to make fairly accurate inferences about the probable state of knowledge of the leader on the basis of the separate experiences that they had been given. Of course, there is no way of knowing if the naive chimpanzees actually understood the exact nature of the visual experience that the leaders had been given, but this series of experiments suggests an ability in chimpanzees to understand that some individual animals possess specific states of knowledge not shared by others.

Premack and Woodruff (1978) explored the attributional ability of a chimpanzee named Sarah. Sarah was allowed to watch videotapes in which human actors tried to solve staged problems. After she was familiarized with a particular videotape, she was given pairs of still photos, one of which represented a solution to the problem. Premack and Woodruff reported that on a wide variety of problems, Sarah correctly selected from the photos the alternative that depicted the solution to the problem with which the actor had been confronted. They argued that her ability to interpret the scenes in the tapes as problems 
to be solved by the actor (inferred from her choice of the correct solutions) required a capacity to make inferences about the intentions of the actors. Like humans, they speculated, chimpanzees may have a theory of mind, an ability to impute mental states to others. In this instance Premack and Woodruff believed that Sarah had demonstrated that she was capable of guessing about the intentions and desires of others. At the time, they also speculated that if chimpanzees are capable of attributing intentions to others, then they may also be capable of making inferences about other mental states, such as guessing and knowing, and suggested some preliminary ways to address this problem. To date, however, the results of such studies have not been published, although some have been noted briefly by Premack (1988).

Another effort to explore the attributional ability of primates has been made by Gallup $(1982,1983,1985)$ who has sketched a broad, comparative approach to understanding the emergence of self-awareness and its potential cognitive byproducts. The ability of chimpanzees to recognize themselves in mirrors was first demonstrated by Gallup (1970), and later reports have confirmed and extended his findings of an inability for gorillas, lesser apes, all species of monkeys tested thus far, and a variety of other animals to do the same (for reviews see Anderson, 1984; Povinelli, 1987). Gallup (1975) has argued that selfrecognition is an empirical measure of self-awareness, or the ability of an organism to become the object of its own attention. More recently, Gallup (1983) has pursued these findings further and has predicted, on the basis of their shared capacity for self-recognition, that chimpanzees and orangutans (like humans) ought to be capable of using their own self-knowledge to make guesses about the self-knowledge of others. Many introspectively based social behaviors (intentional deception, sorrow, grief, empathy, etc.) are believed to develop from the use of one's own experiences to make inferences about the probable experiences that others have under similar conditions (Gallup, 1985). On the other hand, monkeys, for example, are predicted to lack this ability because of their apparent inability to recognize their own selfimages. Hence, Gallup speculated that they do not have a sufficiently well-developed self-concept to support complex inferences about the mental states of others (Gallup, 1983).

Premack (1988) recently stressed the necessity of careful, experimental analyses of these issues if researchers are ever to have closure on the possibility that chimpanzees may possess a theory of mind and on the scope of attributions that they might be capable of making. There are other reasons for developing methodological approaches for addressing these issues aside from mapping the cognitive abilities of chimpanzees. One is to assess the plausibility of the interpretation of social manipulation by primates that Whiten and Byrne (1988) offered. Another reason is that the comparative application of such methodologies will eventually allow us to test more global theories that predict qualitative differences in these abilities among different phyletic groups (Gallup, 1983).

As part of a larger project to evaluate Gallup's (1983) model of the expected distribution of mind in primates, we investigated the possibility that chimpanzees are capable of modeling and understanding the consequences of the visual experiences of others. Our experimental design was inspired by investigations of the onset of this capacity in human children (i.e., Wimmer et al., 1988) and by Premack and Woodruffs (1978) discussion about the distinction between guessing and knowing as different mental states. In light of such efforts, we reasoned that if chimpanzees were given the opportunity to watch two persons, one of whom witnessed an event occur, and another who did not, it might be possible to determine what they knew about the relative knowledge possessed by each of them. Here we report evidence that chimpanzees may be capable of visual perspective taking and possibly of using this ability to differentiate between guessing and knowing. The results are discussed in the context of comparable abilities in human children and the potential for future research. 


\section{Method}

\section{Subjects and Housing}

The subjects were 4 chimpanzees (Fan troglodytes) housed at the Primate Cognition Project of the Ohio State University. At the time of the study, Sheba was 7 years old, Kermit, 9 years, Darrell, 9'/2 years, and Sarah, 28 years. Sheba, Darrell, and Kermit had been part of a variety of previous investigations related to learning and cognition including one-to-one correspondence, color discriminations, the use of colors as attributes, drawing (Boysen, Berntson, \& Prentice, 1987), cross-modal discriminations, same-different concepts, and numerical competence (Boysen \& Berntson, 1989). Sarah arrived at the project 1 year before the beginning of the current study. Before her arrival at the Primate Cognition Project, she had been the subject of over 2 decades of cognitive studies, including linguistic abilities (Premack, 1986), primitive mathematical concepts (Woodruff \& Premack, 1981), and attributional abilities (Premack \& Woodruff, 1978). All subjects were equally familiar with the two experimenters who alternated between the roles described later.

\section{Apparatus}

The apparatus used in this investigation was a modified version of a communication apparatus designed by Mason and Hollis (1962). As they did, we refer to one side of the apparatus as the informant side and the other as the operator side. The operator side had four handles that controlled the movement of four paired food trays. When one of the handles was pulled, the corresponding pair of trays moved in opposite directions to within reach of the participants (Figure 1), The informant side had no such handles, which prevented the participants on this side from controlling the operation of the trays. In this study a removable, opaque plastic food cup was placed upside-down inside each of the eight trays, thus concealing its contents from direct view.

Figure 1. Communication apparatus. (The four pairs of food trays, each covered by an inverted food cup, were controlled by pulling on handles on the far, operator side of the apparatus.)

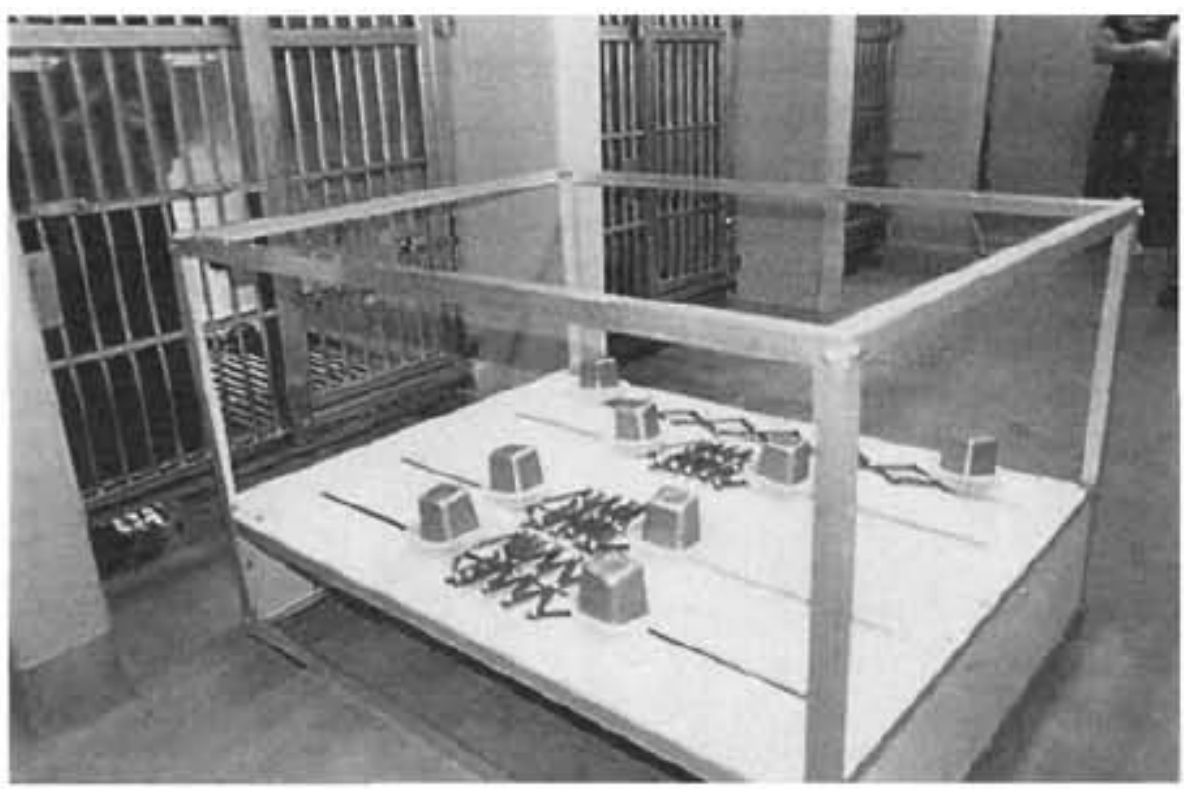


Figure 2. The guesser exits the room.

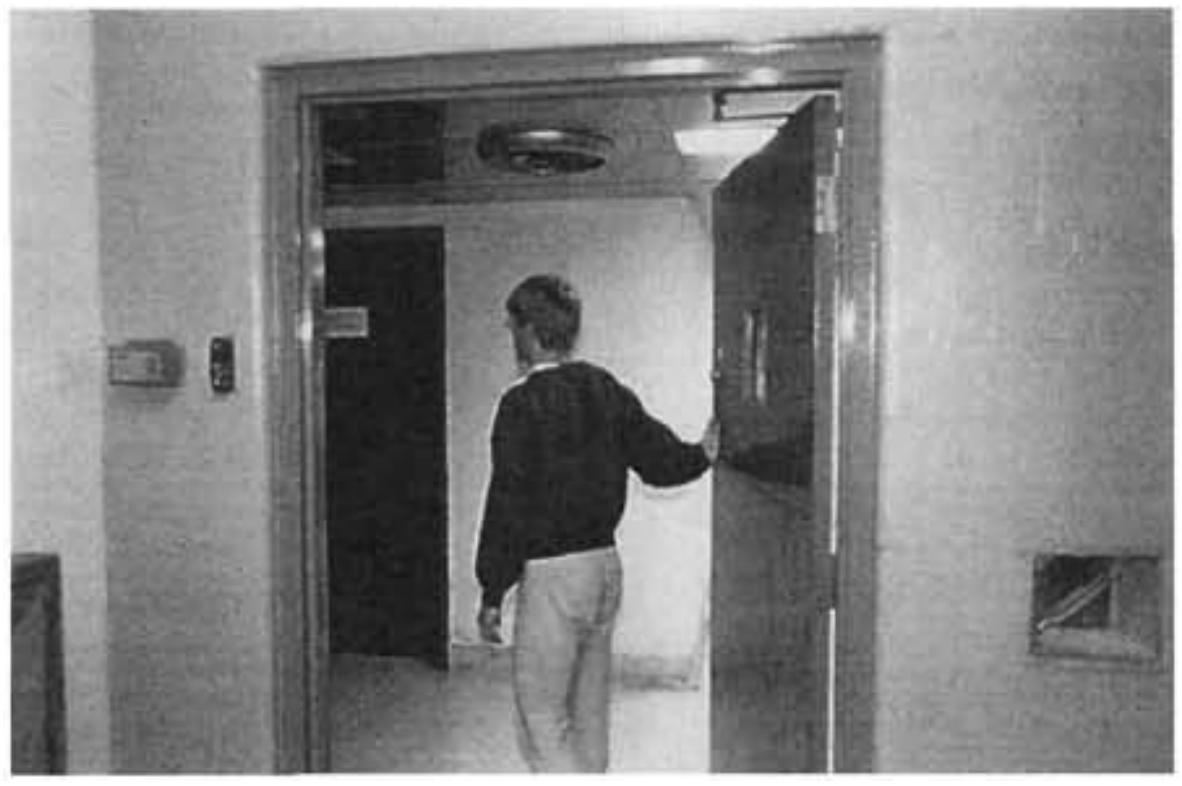

\section{Procedure}

Immediately before this study, all subjects participated in a cooperative role-reversal study with the same apparatus (Povinelli, Boysen, \& Nelson, 1989). During the course of that experiment, all subjects had learned to point to baited food cups inside the trays and to respond to pointing by an experimenter by pulling the correct handle. In Phase 1 of the study, individual subjects sat on the operator side of the apparatus while inside their home cages. Thus, they had access to the four handles that controlled the movement of the trays. The opaque, plastic cups were placed inside all of the empty food trays while the subject watched. Three experimenters participated in the study. One experimenter always operated a removable cardboard hood that covered the food trays. The other two experimenters alternated between two roles, the guesser and the knower. Following a randomized schedule, one of these two experimenters assumed the role of the guesser and left the room while the subject and the other two remaining experimenters remained inside (Figure 2). Next, a hood was placed over the food trays, which prevented the subject but not the experimenters from seeing them. The experimenter who assumed the role of the knower kneeled down and hid a food reward under one of the four cups under the hood either before, during, or after several false baiting movements (Figure 3). During this baiting procedure the subjects could clearly see the knower hiding the food but could not see which food cup it was placed under. The knower then stood up, assumed a neutral posture in a predetermined location behind the apparatus, and fixed his gaze on the front of the subject's cage. The guesser then re-entered the room. At this time, both the guesser and the knower pointed to one of the four locations, and the hood was removed by the other experimenter (Figure 4). The subjects then responded by pulling one of the handles and displaced the cup from the food tray. If they chose the knower, they removed the food cup and obtained the reward. If they chose either the guesser or another cup, they were told that they were wrong and the knower generally indicated that he was correct by displacing the correct food cup, thus revealing its contents. The knower always pointed to the correct location while the guesser always pointed to an incorrect location. The location of food, position of the experimenters, and the incorrect location to which the guesser pointed were all block randomized. The pointing routine had been extensively rehearsed to standardize cues such as distance from the food cups, height and angle of arms and hands, and direction of gaze for both pointers. The subjects received 10 trials per day with these procedures. 
Figure 3. The knower hides the food in one of four food cups.

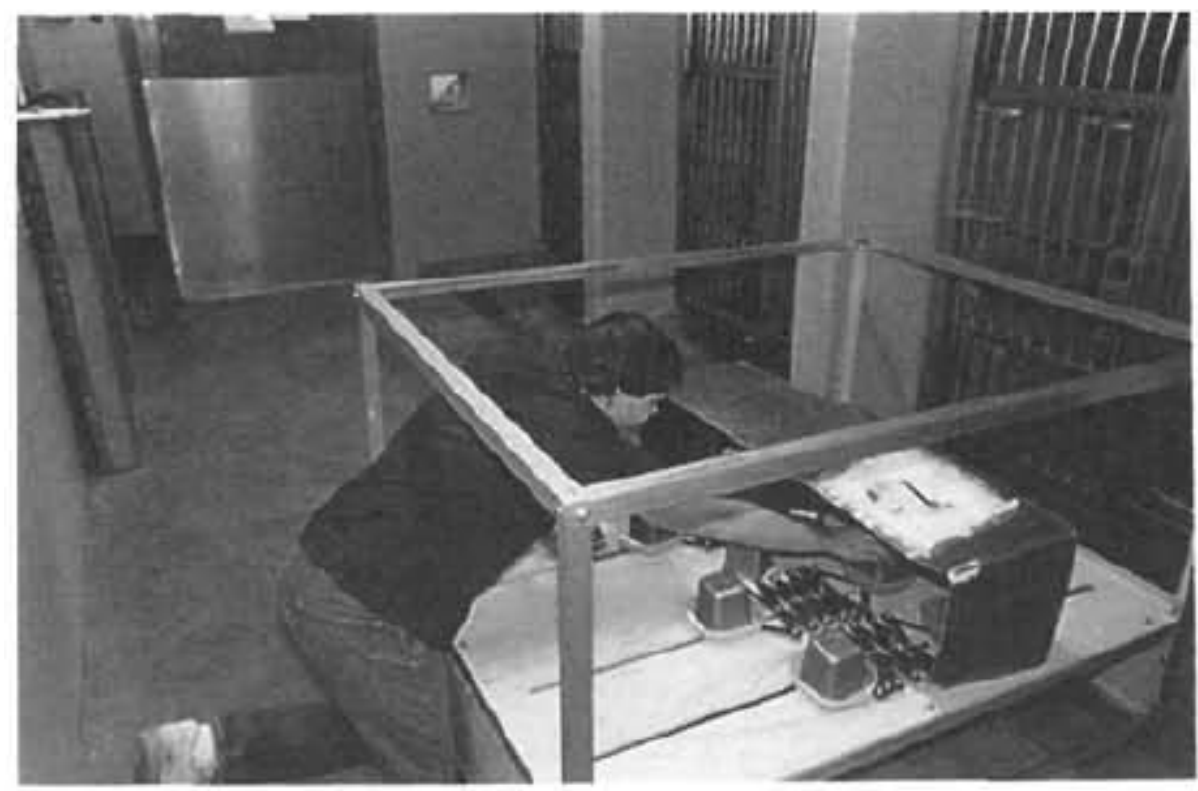

Figure 4. The knower and guesser point to baited and unbaited food cups.

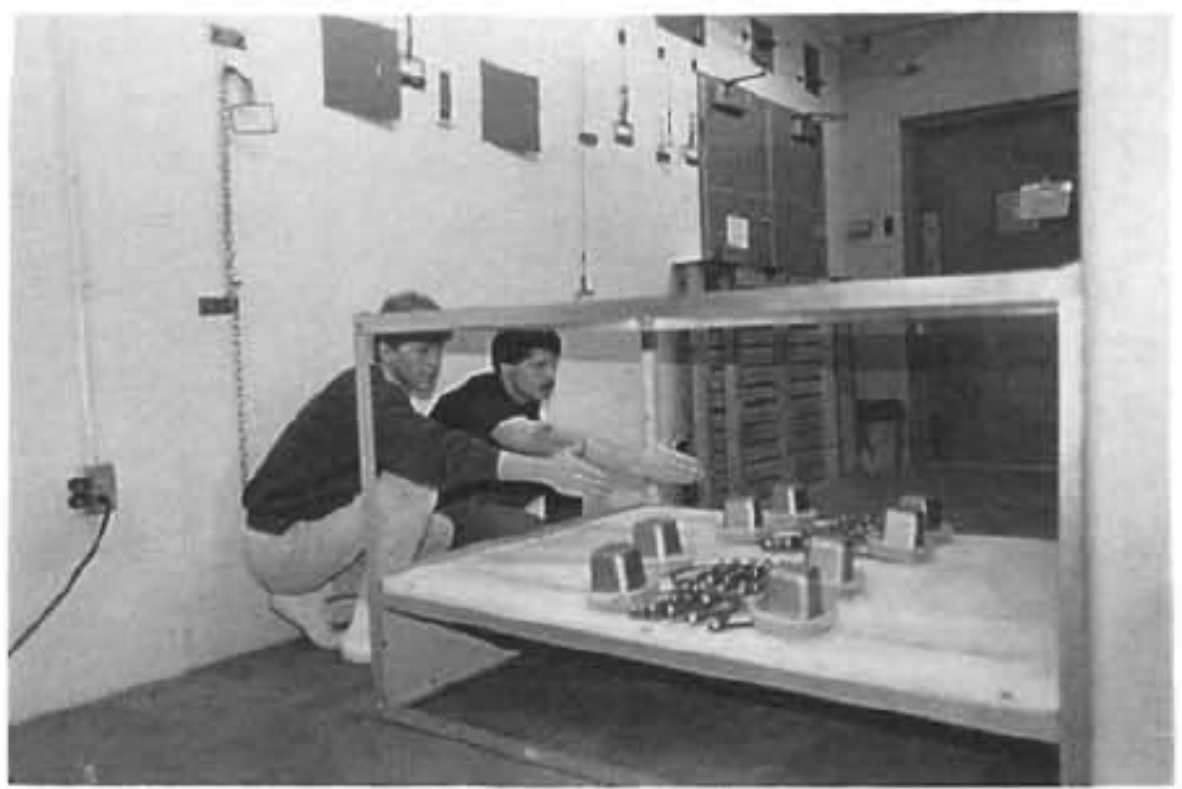

Because the subjects' performances quickly stabilized, at the end of the 3rd week (for Kermit, the 4th week), we altered the procedure by having the knower and the third experimenter wear small blue hats while the baiting and pointing were taking place. One of these hats was conspicuously passed between the two experimenters who played the roles of guesser and knower on each trial that their roles changed. This was done in the hopes of improving the chimpanzees' performance by helping them to remember who had been watching and who was out of the room. Although the addition of the hats did not appear to have a noticeable effect on any of the subjects' performances, a transfer phase (Phase 2) was conducted during which the hats were eliminated from the routine to verify this observation. 
Finally, in order to evaluate what the chimpanzees had learned, a critical transfer phase (Phase 3) was conducted. It consisted of 10 trials on 3 consecutive days in which three variables of the routine were altered. Instead of the guesser's leaving the room and the knower's hiding the food, both the guesser and the knower remained inside the room while the third experimenter hid the food, The guesser and knower stood beside each other, behind the apparatus, and watched as the third experimenter prepared to hide the food. However, just before the food was hidden the guesser placed a large paper bag over his head, which prevented him from seeing where the food was being placed (Figure 5). After the baiting was completed, the guesser lifted the bag off his head. Finally, the hood over the food cups was removed, and the guesser and knower pointed as before. As in the previous phases, all variables were block randomized.

\section{Results}

The results of Phase 1 (Figure 6) reveal that a consistent pattern quickly emerged for all of the subjects, especially Sheba and Darrell. These 2 subjects quickly learned to respond to the information provided by the knower most of the time, despite varying levels of incorrect choices for the guesser and other unbaited trays to which no one was pointing. When the data from Phase 1 was summed across weeks, a chi-square analysis revealed that the individual performances of all 4 subjects differed strongly from chance $(p<.001$ or better). Given this overall effect, a chi-square analysis was then performed on each subject's summed preference for the knower as compared with that for the guesser. All subjects showed a significant preference for choosing the location to which the knower was pointing: Sheba, $X^{2}(1, N=285)$ $=27.79, p<.001$; Darrell, $X^{2}(1, N=291)=14.52, p<.001$; Kermit, $X^{2}(1, N=288)=20.05, p<.001$; and Sarah, $X^{2}(1, N=229)=8.07, p<.005$. In addition to this overall effect, a further analysis of each subject's preference for the knower rather than for the guesser in individual blocks of trials also revealed significant effects. The statistically significant blocks of trials are indicated by the vertical dotted lines in Figure 6 .

As a preliminary assessment of the learning that had occurred during Phase 1, we compared the preferences of each subject for the guesser and knower on their first and last block of trials in this phase. Interestingly, despite their preference for the knower, most of the subjects' scores improved only slightly across the 6 weeks of this phase. Of the 3 subjects who appeared to have understood the essential nature of the task (Darrell, Sheba, and Kermit), only Kermit's performance revealed a significant change from the first to the last block of trials, $X^{2}(2, N=50)=10.97, p<.005$. Thus, both Darrell and Sheba did almost as well on their first block of trials as their last, despite the fact that their results did not reach statistical significance until later (see Figure 6).

The hats were introduced into the routine at the end of Week 3 for Sheba, Darrell, and Sarah, and Week 4 for Kermit. This potential discriminative cue did not appear to have any noticeable effect on the animals' performances, and their transfer into Phase 2 (during which the hats were eliminated) provides additional support for this view. Kermit and Sheba did slightly better, and Darrell did slightly worse, but these changes were minor and not statistically significant. Only Sarah's change in performance from the last block of trials in Phase I to the single block in Phase 2 was significant, $X^{2}(2, N=50)=11.19, p<.005$, and, interestingly, revealed a clear preference for the knower, $X^{2}(1, N=38)=10.53, p<.001$.

The results of Phase 3, in which the guesser covered his head while the food was hidden, showed no decrease in performance for the 3 of the 4 subjects that clearly learned the previous task (Table 1). Darrell, Sheba, and Kermit all responded to the knower significantly more often than the guesser $(p<, 05$ or better), despite the alteration of three critical variables in the experimental design (the presence of the guesser, the nature of the visual obstruction that defined the guesser, and the identity of the person who hid the food). 
Figure 5. Novel procedure used in Phase 3: The guesser places a paper bag over his head during baiting procedure.

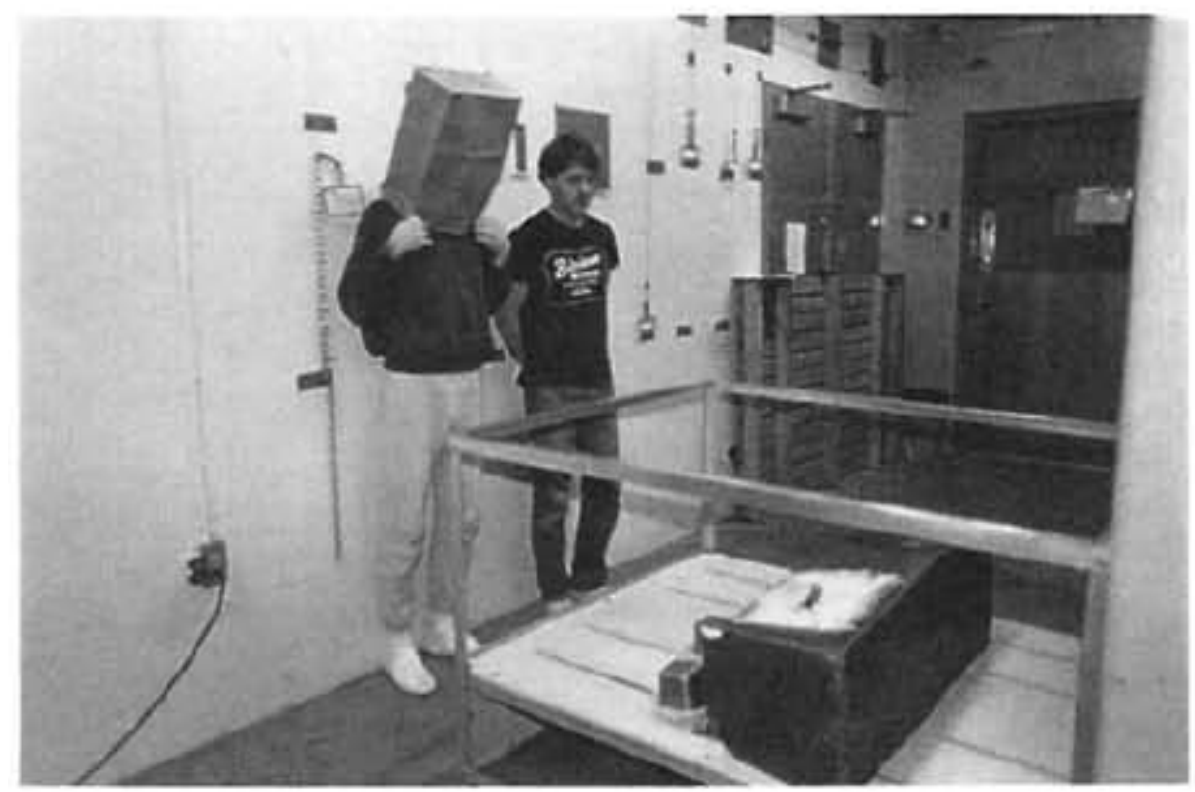

\section{Discussion}

The hypothesis evaluated in this experiment was related to the perspective-taking abilities of chimpanzees. In particular, we asked, are chimpanzees capable of modeling the visual experiences of others? We reasoned that if they are, then they may also understand that there is a difference in knowledge between someone who has seen an event occur and someone who has not and may use this understanding for their own benefit. The chimpanzees' performances in this study provided preliminary support for the existence of such an ability. We therefore adopt the working hypothesis that chimpanzees are capable of visual perspective taking. In particular, the results support a specific implication of this hypothesis, namely, that chimpanzees understand that someone who has seen an event occur has a different state of knowledge about that event than someone who has not.

Before beginning this experiment we postulated two potential outcomes. First, it was possible that the subjects would learn to discriminate between the guesser and the knower in Phases 1 and 2, but when the novel routine was introduced in Phase 3, their scores would drop to chance levels. The other outcome was similar to the first in that the learning would occur in Phases 1 and 2, but it differed in that the subjects would show immediate transfer in Phase 3. At the outset we agreed to view the first possible result as consistent with a more traditional learning theory account of the chimpanzees' performance. Such an outcome may be plausibly explained by suggesting that the subjects had learned to use discriminative cues, such as the person who remained in the room or the one who baited the cups, to solve the problem. Given such results, it would be unnecessary to presume that the subjects had any idea of the specific knowledge possessed by the knower. In contrast, we viewed the second possible outcome as consistent with the view that the chimpanzees used attributional abilities to make an inference about the differing states of knowledge of the guesser and knower on the basis of their different visual experiences. 
In feet, our results are most consistent with the second hypothesized outcome. Three of the 4 subjects showed immediate transfer in the novel test situation during Phase 3. In addition, with the exception of Kermit, there appeared to be little change in learning across the course of the experiment, which further supports the view that the subjects came to understand the nature of the task early in Phase 1.

Although we were not aware of it at the time of this study, Premack (1988) independently shared the same insight, which led him to create a very similar task for 4 juvenile chimpanzees. Unfortunately, the formal results of his experiment have not been published, and thus it is not yet possible to know how his results compare with ours. His design appears to have differed from ours in several important ways. For example, only one of the trainers provided information about the location of the food. This was achieved by tying a string to each trainer and allowing the subject to pull one of the trainers forward. This trainer then pointed to one of the cups. The description Premack outlined suggests that 2 of his subjects performed in a fashion similar to Darrell, Kermit, and Sheba, and did so within a mere 24 trials. This suggests that forcing chimpanzees to choose between simultaneous, contradictory information (as in our study) may hinder their ability to express their comprehension of the task. This may be due to the great social force that pointing may exert on their behavior (Premack, 1986).

A more parsimonious interpretation of our results may be that the subjects were responding to cues related to the intensity of the pointing of the guesser and knower from the very beginning. We view this as unlikely for a variety of reasons. First, on a majority of trials, the subjects carefully tracked the movements of the guesser and knower. Because of the counterbalanced nature of the pointing routine, it was often necessary for the guesser and knower to cross paths as they moved into position. The chimpanzees moved accordingly and generally correctly seated themselves in front of the knower before the pointing had occurred. In addition, on a large portion of these trials, they grasped the wrong handle before the hood was removed but then quickly corrected themselves once they were able to see exactly where the knower was pointing. In other words, they appeared to select in advance the person they wished to respond to and waited for the hood to be removed to see which food cup was correct Thus, the pointing itself did not appear to be the variable that the subjects used to select the knower, but rather it appeared to be the cue that the subjects used to ascertain the exact location of the food. In addition to these observations, we also have empirical evidence from a subsequent experiment (with the same apparatus) that even after 200 trials the subjects could not discriminate between intentionally misleading pointing by an experimenter who had seen where the food was hidden and accurate pointing by the same person. This is an important point because it strongly implies that unconscious cues, if present, played a minor role in our results.

Even if such unconscious cues were relatively unimportant, this does not rule out the possibility that the chimps learned other rules such as select the person who stays in the room or select the person who hides the food. Indeed, we strongly suspect that they did learn these rules. Although such rules do not require that the subjects understand the relation between seeing and knowing, they certainly play a part in the behavior of any organisms, including humans, that do understand this causal relation. Unless one first realizes that there are two conditions to which the guesser and knower are being subjected (inside the room vs. outside the room or paper bag over the head vs. no paper bag over the head), there can be no basis for making inferences about the state of knowledge that results from those conditions. The recognition of such conditions alone may be an insufficient explanation of the results. The immediate ability of the subjects to perform accurately when the paradigm was altered, combined with the relatively weak learning curves in Phase 1, leads us to favor the hypothesis that chimpanzees, like young children, believe that those who see an object or event have a different understanding of that object or event than others who do not see it. However, like Premack and Woodruff (1978) and Gallup (1982), we recognize that a single experiment cannot definitively establish the presence of such capacities. We do not regard 
this as a trivial point, because no one experiment can clearly disentangle the effects of learning on the subjects' behavior. Instead, convergent evidence is necessary to establish that a specific attributional process is present.

Figure 6. Performance by subject across all three phases of the experiment. (The blocks of trials in which the subjects showed a statistically significant preference, $p<.05$ or better, for responding to the knower are indicated by the vertical dotted lines. Data is presented in blocks of 50 trials for Phases 1 and 2. Phase 3 consisted of 30 trials. Subjects were given 10 trials each day.)
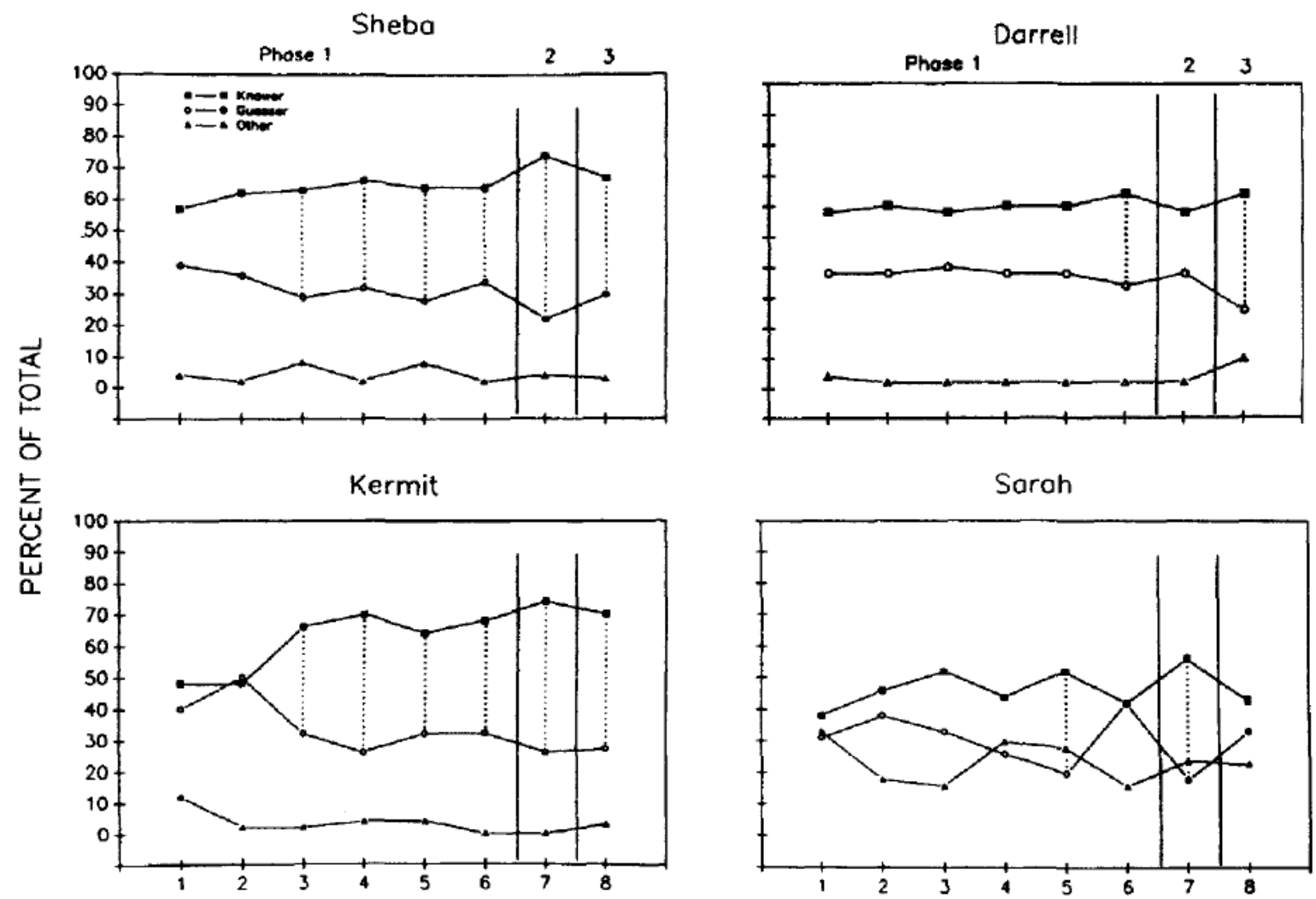

BLOCKS OF 50 TRIALS

Table 1. Results of Phase 3

\begin{tabular}{|c|c|c|c|c|c|}
\hline \multirow[b]{2}{*}{ Subject } & \multicolumn{3}{|c|}{ Choice } & \multirow[b]{2}{*}{$X^{2}(1)$} & \multirow[b]{2}{*}{$N$} \\
\hline & Knower & Guesser & Other & & \\
\hline Darrell & 19 & 8 & 3 & $4.48^{\star}$ & 27 \\
\hline Kermit & 21 & 8 & 1 & $5.82^{\star \star}$ & 29 \\
\hline Sheba & 20 & 9 & 1 & $4.16^{\star}$ & 29 \\
\hline Sarah & 13 & 10 & 7 & 0.26 & 23 \\
\hline
\end{tabular}

Note. Each subject was given 30 trials. The chi-square comparisons are between choices for guesser and knower only.

${ }^{\star} p<.05 .{ }^{* \star} p<.025$. 
One may reasonably wonder why, if chimpanzees understand that seeing leads to knowing, they continue to choose the guesser at all. Even during the best block of performance by Kermit, the guesser was still chosen one fourth of the time. In Phase 1, Darrell chose the knower $62 \%$ of the time and the guesser $38 \%$ of the time. This may either argue against their complete comprehension of the problem or point to other factors that may account for their inability to always reject the information provided by the guesser. Clearly, even if our working hypothesis is correct, it does not necessarily mean that a chimpanzee's understanding of the causal nature of knowledge acquisition is equivalent in all respects to that of humans. Current speculations about this differ. Premack (1988) envisioned that chimpanzees almost certainly have a weaker theory of mind, capable of attributing only a small subset of the mental states that humans are capable of projecting. Gallup (1983), on the other hand, predicted a more generalized attributional capacity, which extends into many different domains. Regardless of the breadth of the chimpanzee's attributional abilities, however, we offer the prediction that these abilities, if present, are likely to be inherently less stable than those found in humans, in part because of attentional and emotional differences between the two species. For example, we believe that Sarah's performance resulted from the combined interaction of emotional and attentional processes on her understanding of the task (i.e., perseveration biases, emotional reactivity when she was wrong, etc.). To a lesser degree, these factors may have affected the performances of the other subjects as well.

One interesting aspect of the design of our experiment is that it not only addresses the issue of visual perspective taking but also a more sophisticated issue of whether an animal is able to understand that access to visual information leads to knowledge-the cognitive underpinnings of an ability to discriminate between guessing and knowing. In this regard, most studies of human children have been restricted to examinations of their visual perspective-taking abilities. Some form of visual perspective taking emerges in young children by about 2 years of age (Lempers et al., 1977; Masangkay et al., 1974). This early ability appears to be fairly restricted, however, merely allowing the infant to infer what object another person can or cannot see (Lempers et al., 1977). Only later, by about 4 years of age, do children begin to appreciate that the visual perspective of another determines how that object appears to them. That is, a second developmental stage emerges that enables children to make more complete and detailed inferences about the visual perspectives of others (Flavell, 1974; Lempers et al., 1977; Masangkay et al., 1974).

More recently, there have been attempts to determine at what age children come to understand that access to information leads to knowledge or at what age the child develops a causal theory of knowledge acquisition. Wimmer et al. (1988) reported that children do not fully understand visual informational access as a source of knowledge until they are 4 years old. They discovered that at 3 years of age most children did not consider another person's visual informational access in assessing what that person knew or did not know. The task in this experiment may have required such an ability because the subjects were asked to judge between a person who had visual access to a specific piece of information and one who did not. Thus, one implication of our working hypothesis is that the chimpanzees were using attributional abilities that begin to develop in human children sometime between 3 and 4 years of age. Unfortunately, there have been no experimental studies in which children have been required to make a simultaneous discrimination between guessing and knowing in others. However, an analysis of the use of the words guess and know by preschool children has revealed that these terms are not fully understood until about age 4 (Misciones, Marvin, O'Brien, \& Greenberg, 1978). A replication of this experiment with young children may be useful for purposes of clarifying the chimpanzees' performance.

A question left unresolved by our study is to what extent the chimpanzees were capable of understanding the concept of guessing. Although they clearly responded preferentially to the knower, their comprehension of what the guesser was doing remains uncertain. If the subjects did make an attribution 
about the guesser's state of knowledge, they may have either concluded that he did not know where the food was hidden (which, of course, is untrue), or they may have believed that he did know but was intentionally misinforming them. There is some precedent for believing that chimpanzees are capable of understanding that they are being deceived (Woodruff \& Premack, 1979), and we are currently analyzing the results of a subsequent experiment we conducted to help to distinguish between these possibilities. At present, we recognize that our use of the term guesser is merely a suggestive gloss for the role of the experimenter who pointed to the incorrect location.

Even though the results of this study support the emerging body of evidence that chimpanzees are capable of making at least some inferences about the mental states of others, we believe the best method for resolving these issues is a convergent and comparative one. In fact, this experiment only addresses a small subset of the question of attributional abilities of primates, specifically, the relation between seeing and knowing and the distinction between guessing and knowing. There are clearly many other dimensions to this general phenomenon, not all of which hinge on determining if the chimpanzee understands the sources of private knowledge as we have approached the issue in this study. For example, if chimpanzees do possess a theory of mind, they may attribute responsibility to others for intentional actions, but not accidental ones, in much the same fashion as do 3-year-old human children (Yuill \& Perner, 1988). We are currently investigating this possibility by examining the chimpanzees' responses to two classes of actors, those who accidentally cause something undesirable to happen, and those who cause the same thing to happen on purpose.

Psychologists interested in the development of attributional capacities in human infants have made considerable and intriguing progress, and in principle, there is no reason why these approaches cannot be modified to study the nature of animal cognition as well. Granted, the essential questions cannot be answered by simply asking the animals what they think (as we can with children), but creative approaches can be developed to pose equivalent questions that allow the subjects to express what they know through their behavior. The problem is a difficult one and requires that a careful balance be struck between identifying the objective cues that must necessarily support even the most complex attributional processes and ensuring that these cues are not sufficient to produce the behaviors in question. However, an approach that constructs and empirically evaluates theories that make explicit predictions about behavior depending on the presence or absence of specific attributional capacities is a critical point of departure. Only after such investigations have been completed will it be possible to evaluate the validity of alternative approaches that rely on detailed anecdotes as evidence of attributional abilities (Whiten \& Byrne, 1988) and of others that argue such issues are largely irrelevant (Epstein, Lanza, \& Skinner, 1981; Skinner, 1987).

One model that explicitly predicts dramatic differences between apes and humans, on the one hand, and monkeys, on the other, in experiments similar to ours already exists (Gallup, 1983). Studies are currently underway to address these predictions by attempting to replicate our findings with rhesus macaques. A comparative application of such experimental methods offers the hope of eventually characterizing the distribution of attributional abilities in nonhuman primates.

\section{References}

Anderson, J. A. (1984). Monkeys with mirrors: Some questions for primate psychology. International Journal of Primatology, 5. 81-98.

Bachmann, C, \& Rummer, H. (1980). Male assessment of female choice in hamadryas baboons. Behavioral Ecology and Sociobiotogy, 6, 315-321.

Borke, H. (1971). Interpersonal perception of young children: Egocentrism or empathy? Developmental Psychology, 5, 263-269. 
Boysen, S. T., \& Berntson, G. G. (1989). Numerical competence in a chimpanzee (Pan troglodytes). Journal of Comparative Psychology, 103, 23-31.

Boysen, S. T., Berntson, G. G., \& Prentice, J. (1987). Simian scribbles: A reappraisal of drawing in the chimpanzee (fan troglodytes). Journal of Comparative Psychology, 101, 82-89.

Cheney, D., Seyfarth, R., \& Smuts, B. (1986). Social relationships and social cognition in nonhuman primates. Science, 234, 1361-1366.

deWaal, F. (1986). Deception in the natural communication of chimpanzees. In R. W. Mitchell \& N. S. Thompson (Eds.), Deception: Perspectives on human and nonhuman deceit (pp. 221-244). Albany: State University of New York Press.

Epstein, R., Lanza, R. P., \& Skinner, B. F. (1981). "Self-awareness" in the pigeon. Science, 212, 695-696.

Flavell, J. H. (1974). The development of inferences about others. In T. Mischell (Ed.), Understanding other persons (pp. 66-116). Oxford: Blackwell.

Gallup, G. G., Jr. (1970). Chimpanzees: Self-recognition. Science, 167, 86-87.

Gallup, G. G., Jr. (1975). Toward an operational definition of self-awareness. In R. H. Turtle (Ed.), Socioecology and psychology of primates (pp. 309-341). The Hague, the Netherlands: Mouton.

Gallup, G. G., Jr. (1982). Self-awareness and the emergence of mind in primates. American Journal of Primatology, 2, 237-248.

Gallup, G. G., Jr. (1983). Toward a comparative psychology of mind. In R. E. Mellgren (Ed.), Animal cognition and behavior (pp. 473-510). New York: North Holland.

Gallup, G. G., Jr. (1985). Do minds exist in species other than our own? Neuroscience and Biobehavioral Reviews, 9, 631-641.

Humphrey, N. K. (1980). Nature's psychologists. In B. Josephson \& B. S. Ramachandra (Eds.), Consciousness and the physical world (pp. 57-80). New York: Pergamon.

Kummer, H. (1967). Tripartite relations in hamadryas baboons. In S. A. Altmann (Ed.), Social communication among primates (pp. 67-71). Chicago: University of Chicago Press.

Lempers, J. D., Flavell, E. R., \& Flavell, J. H. (1977). The development in very young children of tacit knowledge concerning visual perception. Genetic Psychology Monographs, 95, 3-53.

Masangkay, Z. S., McKluskey, K. A., Mcmtyre, C. W., Sims-Knight, J., Vaughn, B. E., \& Flavell, J. H. (1974). The early development of inferences about the visual precepts of others. Child Development. 45, 357-366.

Mason, W. A., \& Hollis, J. H. (1962). Communication between young rhesus monkeys. Animal Behaviour, 10, 211-221.

Menzel, E. W., Jr. (1974). A group of young chimpanzees in a one-acre field. In A. Schrier \& F. Stollnitz (Eds.), Behavior of nonhuman primates: Modern research trends (Vol. 5, pp. 83-153). New York: Academic Press.

Misciones, J. L., Marvin, R. S., O'Brien, R. G., \& Greenberg, M. T. (1978). A developmental study of preschool children's understanding of the words "know" and "guess." Child Development, 49, 1107-1113.

Mitchell, R. W. (1986). A framework for discussing deception. In R. W. Mitchell \& N. S. Thompson (Eds.), Deception: Perspectives on human and nonhuman deceit (pp. 3-40). Albany: State University of New York Press.

Mossier, D. G., Marvin, R. S., \& Greenberg, M. T. (1976). Conceptual perspective taking in 2- to 6-year old children. Developmental Psychology, 12, 85-86.

Povinelli, D. J. (1987). Monkeys, apes, mirrors and minds: The evolution of self-awareness in primates. Human Evolution, 2, 493-507.

Povinelli, D. J., Boysen, S. T., \& Nelson, K. E. (1989, May). Chimpanzees: Evidence of perspective-taking through role reversal. Paper presented at the 61st Meeting of the Midwestern Psychological Association, Chicago.

Premack, D. (1986). Gavagai! London: Cambridge University Press. 
Premack, D. (1988). 'Does the chimpanzee have a theory of mind' revisited. In R. Byrne \& A. Whiten (Eds.), Machiavellian intelligence: Social expertise and the evolution of intellect in monkeys apes and humans (pp. 160-179). New York: Oxford University Press.

Premack, D., \& Woodruff, G. (1978). Does the chimpanzee have a theory of mind? Behavioral and Brain Sciences, 4, 515-526.

Smuts, B. (1986). Sex and friendship in baboons. New York: Aldine.

Skinner, B. F. (1987). What ever happened to psychology as the science of behavior! American Psychologist, 42. 780-786.

Whiten, A., \& Byrne, R. W. (1988). Tactical deception in primates. Behavioral and Brain Sciences, 11, 233-244.

Wimmer, H., Hogrefe, G. J., \& Perner, J. (1988). Children's understanding of informational access as a source of knowledge. Child Development, 59, 386-396.

Woodruff, G., \& Premack, D. (1979). Intentional communication in the chimpanzee: The development of deception. Cognition, 7, 333-362.

Woodruff, G., \& Premack, D. (1981). Primitive mathematical concepts in the chimpanzee: Proportionality and numerosity. Nature, 293, 568-570.

Yuill, N., \& Pemer, J. (1988). Intentionality and knowledge in children's judgments of actor's responsibility and recipient's emotional reaction. Developmental Psychology, 24, 358-365.

Zahn-Waxier, C., Radke-Yarrow, M., \& Brady-Smith, J. (1977). Perspective-taking and prosocial behavior. Developmental Psychology, 13, 87-88. 